\title{
The Use of Unmanned Aerial Vehicle for Geothermal Exploitation Monitoring: Khankala Field Example
}

\author{
Sergey V. Cherkasov', Anvar M. Farkhutdinov"2, Dmitriy P. Rykovanov, \\ Arbi A. Shaipov ${ }^{4}$ \\ ${ }^{1}$ Vernadsky State Geological Museum, 125009, Mokhovaya Street 11/11, Moscow, Russia \\ e-mail: s.cherkasov@sgm.ru \\ ${ }^{2}$ Department of Geology and Geomorphology, Geograhpical Faculty, Bashkir State University, 450076, \\ Zaki Validi Street 32, Ufa, Russia \\ e-mail: anvarfarh@mail.ru \\ ${ }^{3}$ Geoscan Ltd, 194021, Shatelena Street 26A, St.-Petersburg, Russia \\ e-mail: d.rykovanov@geoscan.aero \\ ${ }^{4}$ Grozny State Oil Technical University named after M. D. Millionshikov, 364051, \\ Isaev Square 100, Grozny, Russia \\ e-mail: a.shaipov@gmail.com
}

Cite as: Cherkasov, S. V., Farkhutdinov, A. M., Rykovanov, D. P., Shaipov, A. A., The Use of Unmanned Aerial Vehicle for Geothermal Exploitation Monitoring: Khankala Field Example, J. sustain. dev. energy water environ. syst., 6(2), pp 351-362, 2018, DOI: https://doi.org/10.13044/j.sdewes.d6.0196

\begin{abstract}
The article is devoted to the use of unmanned aerial vehicle for geothermal waters exploitation monitoring. Development of a geothermal reservoir usually requires a system of wells, pipelines and pumping equipment and control of such a system is quite complicated. In this regard, use of unmanned aerial vehicle is relevant. Two test unmanned aerial vehicle based infrared surveys have been conducted at the Khankala field (Chechen Republic) with the Khankala geothermal plant operating at different regimes: during the first survey - with, and the second - without reinjection of used geothermal fluid. Unmanned aerial vehicle Geoscan 201 equipped with digital (Sony DSX-RX1) and thermal imaging (Thermoframe-MX-TTX) cameras was used. Besides different images of the geothermal plant obtained by the surveys, 13 thermal anomalies have been identified. Analysis of the shape and temperature facilitated determination of their different sources: fire, heating systems, etc., which was confirmed by a ground reconnaissance. Results of the study demonstrate a high potential of unmanned aerial vehicle based thermal imagery use for environmental and technological monitoring of geothermal fields under operation.
\end{abstract}

\section{KEYWORDS}

Renewable energy, Geothermal waters, Monitoring, Unmanned aerial vehicle, Thermal imaging.

\section{INTRODUCTION}

At the present time, great attention is paid to renewable energy and in particular geothermal waters, under the circumstances of steady reduction of traditional resources. Compared to other energy sources such as coal, natural gas, and even some renewables,

\footnotetext{
* Corresponding author
} 
geothermal energy emerges as one of the cleanest and most environmentally benign forms of energy [1]. Abundant global geothermal resources can provide an environmentally friendly source of energy, simultaneously offering reliability and a source of baseload power [2]. However, achieving sustainability in the development of such a complex resource requires an integrated approach, including geological, hydrogeological, geochemical studies and assessment of groundwater temperature changes in case of cooled brine reinjection. Besides, an environmental monitoring should be also conducted to prevent possible negative consequences, including leakage of saline water onto the surface [3]. Conventional in-situ methods may not always be feasible and cost-effective. In this regard, use of remote sensing is relevant: in contrast to on-site observation, remote sensing is the acquisition of information about an object or phenomenon without making physical contact. Remote sensing in a broad sense refers to the study of the Earth's surface at a distance using surveys from space-borne, airborne and other vehicles. The essence of these methods is the interpretation of the results of electromagnetic radiation measurement in a wide spectral range, which is reflected or radiated by an object and recorded at some point remote from it. This technique of information gathering has been actively implemented in all areas of science.

The appropriate remote sensing method for geothermal waters exploration, exploitation monitoring and other means of use is thermal imaging, as they represent a fluid of temperature higher than the ambient. Thermal infrared imagery can be used to detect geothermal features, potential surface indicators of unsustainable fluid extraction [4], anthropogenic disturbances related to geothermal fluid production [5], short-term and long-term monitoring, etc.

The first thermal imaging application was used during the Second World War to detect camouflaged military tools and installations [6]. Its use in geothermal areas exploration began in 1960s. The pioneers were New Zealand and Iceland. Dawson and Dickson [7] in 1970 published results of research on thermal areas heat flow in the North Island of New Zealand. The same year Icelandic scientists [8] conducted infrared surveys of Reykjanes and Torfajökull thermal areas. At the Kverkfjöll, Iceland, Friedman et al. [9] used aerial infrared thermographic and field reconnaissance data for advection heat transfer estimation. Remote sensing thermal imagery was used generally for mapping geothermal features, using either broadband [10] or multispectral instruments [11]. As an example of recent studies, Seielstad and Queen [12] used airborne multispectral midwave- (MWIR: 3.6-5.1 $\mu \mathrm{m}$ ) and longwave-infrared (8.1-12.4 $\mu \mathrm{m}$ ) data for monitoring the Norris Geyser Basin (Yellowstone National Park). The second most common use of remote sensing thermal imagery is estimation of the heat loss with satellite [13] and airborne data [14].

A number of studies have used Advanced Spaceborne Thermal Emission and Reflection Radiometer (ASTER) data to detect surface geothermal anomalies [15]. However, due to resolution limitations, with pixel size being 90 by $90 \mathrm{~m}$, satellite remote sensing of geothermal areas has not been useful for detailed mapping [6]. Factors such as albedo, topographic slope, emissivity and thermal inertia affect the temperature changes of Earth surfaces and these variations potentially mask subtle temperature anomalies related to subsurface geothermal heating in spaceborne data [16].

On the over hand airborne remote sensing methods vehicles and instruments are expensive to buy, operate and maintain. Applying of Unmanned Aerial Vehicles (UAV) can be an alternative.

UAV technologies, as remote sensing itself, have evolved primarily because of military uses, then begun finding wide application among civilian users for earth sensing reconnaissance and scientific data collection purposes [17]. The past few years have seen a fast evolution and availability of UAVs [18]. 
In 2016, Nishar et al. [19] applied UAV thermal imagery and protogrammetry for mapping and capturing detailed information of geothermal surface features and surrounding vegetation within the Wairakei-Tauhara geothermal field (New Zealand). In another research conducted in New Zealand, a $2.2 \mathrm{~km}^{2}$ georeferenced, temperature-calibrated thermal orthophoto of the Waikite geothermal area was created. Mapping was done by drone with thermal infrared camera [20]. Despite the battery life, navigation capabilities and flight regulations limiting UAV application, remote sensing using UAV has several main advantages: high resolution data (due to possibility of low-altitude flights), relatively low cost compared to manned aircraft, flight duration, rapidity, etc. For geothermal energy domain this technology allows for the rapid, safe and cost-effective survey of thermal areas, often present in inaccessible or dangerous terrain [20].

There are a number of other published studies on UAV thermal imagery geothermal application, but there is no research covering subject of geothermal plant monitoring in operation. In 2016, a survey using an UAV equipped with digital and thermal imaging cameras was conducted at the Khankala geothermal field (Chechen Republic) and adjacent territory. For the first time aerial infrared survey was carried out over a geothermal plant functioning in different regimes: with and without reinjection of the used geothermal water. This article presents the results of the photo- and thermal infrared imaging as a possible method for monitoring of geothermal waters exploitation. All the thermal anomalies revealed by the survey have been verified by ground observations, described and classified by sources.

\section{MATERIALS AND METHODS}

Remote sensing by aircraft and space vehicles is a rapidly developing domain in the frame of environmental territories. Carrying out aerial surveys using UAV is considered to be a promising method. Recent technological advances, allowing equipping UAV by Global Positioning Systems (GPS) and digital cameras, have significantly reduced the cost of image acquisition [21]. These complexes can be used both independently and in a multi-level remote sensing analysis. Independent use of the UAV allows solving the following tasks [22]:

- Providing prompt ecological mapping;

- Conducting remote diagnostics of engineering structures;

- Carrying out environmental monitoring;

- Collecting data for a GIS of various levels and purposes.

The goal of this study was to evaluate the possibility of using UAV for environmental monitoring of a geothermal plant in operation and surrounding area. An UAV Geoscan 201 (Table 1, Figure 1) equipped with photo- and infrared cameras has been used for the purpose. The UAV flight duration is about 3 hours, which, with the flight speed of $80 \mathrm{~km} / \mathrm{h}$, allows covering relatively large territories.

Table 1. Unmanned aerial vehicle Geoscan 201 characteristics

\begin{tabular}{c|c}
\hline Flight duration & Up to 3 hours \\
Route maximum length & $210 \mathrm{~km}$ \\
1 flight survey area & $7-22 \mathrm{~km}^{2}$ \\
Recommended allowable wind speed & $\mathrm{Up} \mathrm{to} 10 \mathrm{~m} / \mathrm{s}$ \\
Max. allowable wind speed & $12 \mathrm{~m} / \mathrm{s}$ \\
Take-off preparation time & $10 \mathrm{~min}$ \\
Flight speed & $8-40 \mathrm{~m} / \mathrm{s}$ \\
Maximum takeoff weight & $8.5 \mathrm{~kg}$ \\
Maximum payload mass & $1.5 \mathrm{~kg}$ \\
Motor & Brushless electric \\
Minimum safe flight height & $100 \mathrm{~m}$ \\
Maximum altitude & $4,000 \mathrm{~m}$ \\
Operating temperature & -20 to $+40{ }^{\circ} \mathrm{C}$ \\
\hline
\end{tabular}




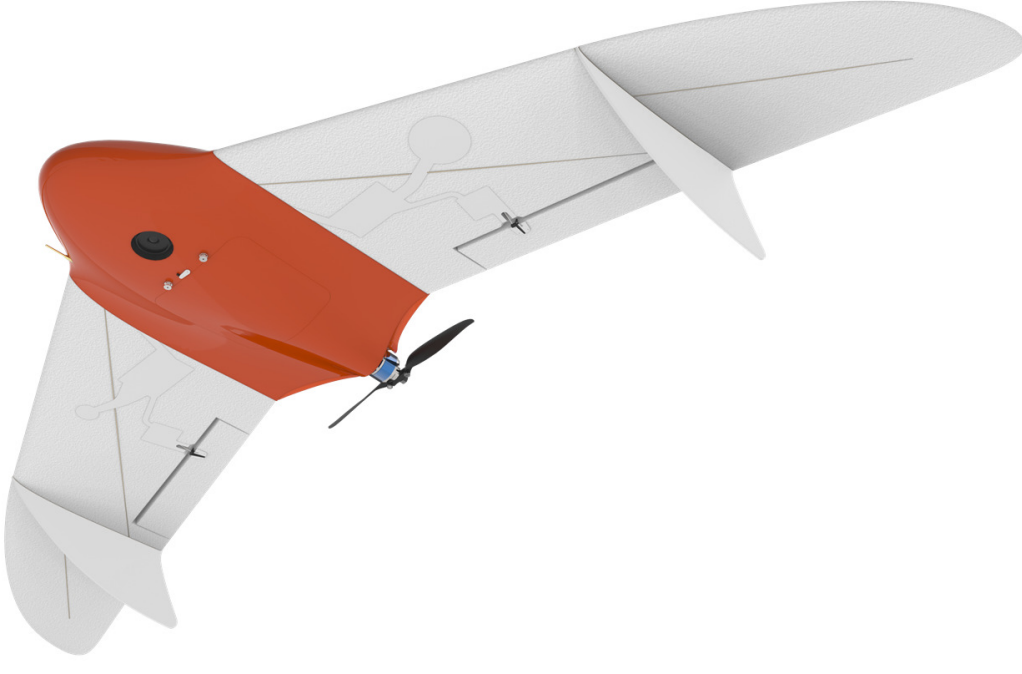

Figure 1. Unmanned aerial vehicle Geoscan 201

The launch from a catapult and landing with a parachute makes the use of the UAV possible without any infrastructure. The complex is fully automatic and ground control plant facilitates monitoring of all stages of the flight (Figure 2).

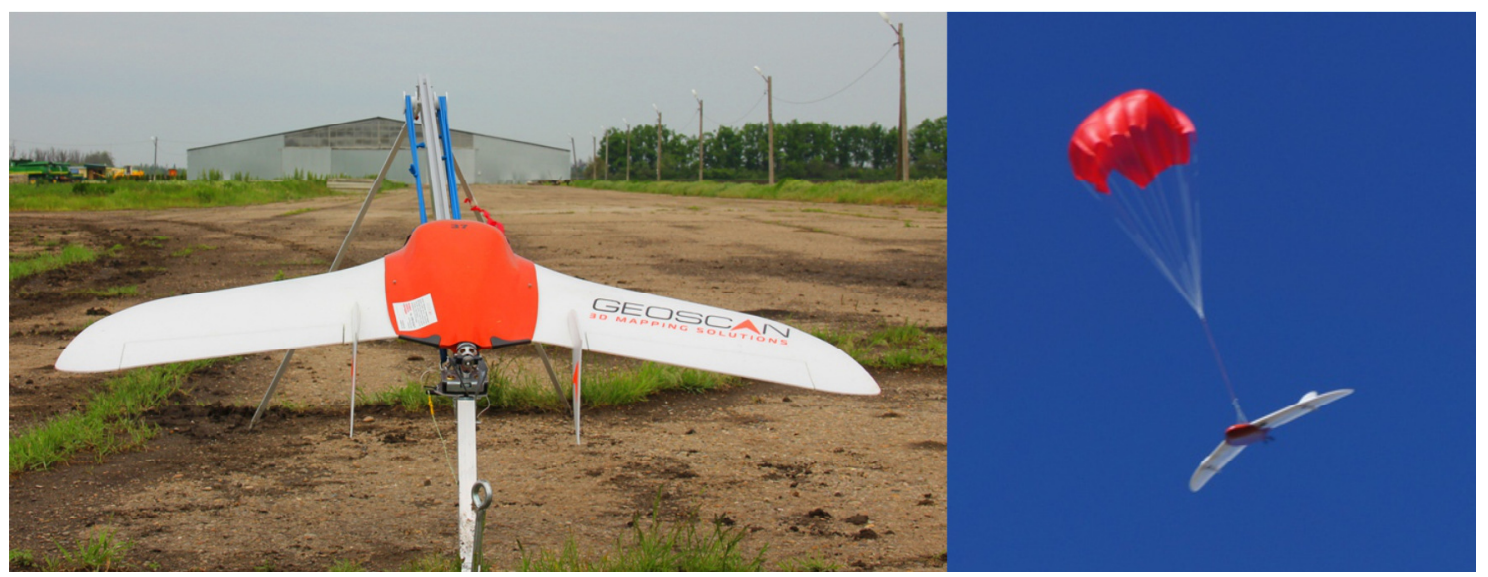

Figure 2. Unmanned aerial vehicle Geoscan 201 launching and landing

The UAV is capable of carrying up to $1 \mathrm{~kg}$ payload and recording imagery information in different spectral ranges. During the experiment, thermal imager Thermoframe-MX-TTX (Table 2) and digital camera Sony DSX-RX1 (24 megapixels, $35 \mathrm{~mm}$ lens, full-size matrix, central shutter) represented the payload. The cameras were synchronized during the survey.

Fog, smoke and rain can severely limit thermal imaging application. In addition, it is not desirable to perform it on a sunny day due to overheating of the external surfaces. Best conditions are in the morning or evening hours, immediately after sunset.

Table 2. Thermoframe-MX-TTX main technical characteristics

\begin{tabular}{ccccccc}
\hline Detector & Matrix type & $\begin{array}{c}\text { Spectral } \\
\text { range }\end{array}$ & $\begin{array}{c}\text { Ambient } \\
\text { temperature }\end{array}$ & Zoom & $\begin{array}{c}\text { Image } \\
\text { refresh rate }\end{array}$ & $\begin{array}{c}\text { Image } \\
\text { representation }\end{array}$ \\
\hline $\begin{array}{c}\text { Microbolometer } \\
\text { matrix }\end{array}$ & $\begin{array}{c}640 \times 480 \text { pixels, } \\
17 \mu \mathrm{m}\end{array}$ & $8-14 \mu \mathrm{m}$ & -40 to $+60{ }^{\circ} \mathrm{C}$ & $4 \times$ & $25 \mathrm{~Hz}$ & $\begin{array}{c}\text { Black and white, } \\
\text { color }\end{array}$ \\
\hline
\end{tabular}

Survey is done in different stages: 
- Route preparation. The route was calculated automatically based on the parameters of the matrix and thermal optics: focal length of $25 \mathrm{~mm}$, resolution of $640 \times 480$;

- Data acquisition. Imaging took place in accordance with the GeoScan Planner software algorithms, which is part of the UAV ground control plant (Figure 3), based on the need of $70 \%$ overlap between adjacent frames. The flight task is loaded into the autopilot and the flight is conducted in automatic mode according to coordinates. Synchronous shooting with both, thermal imager and digital camera is performed, cameras are nadir-directed;

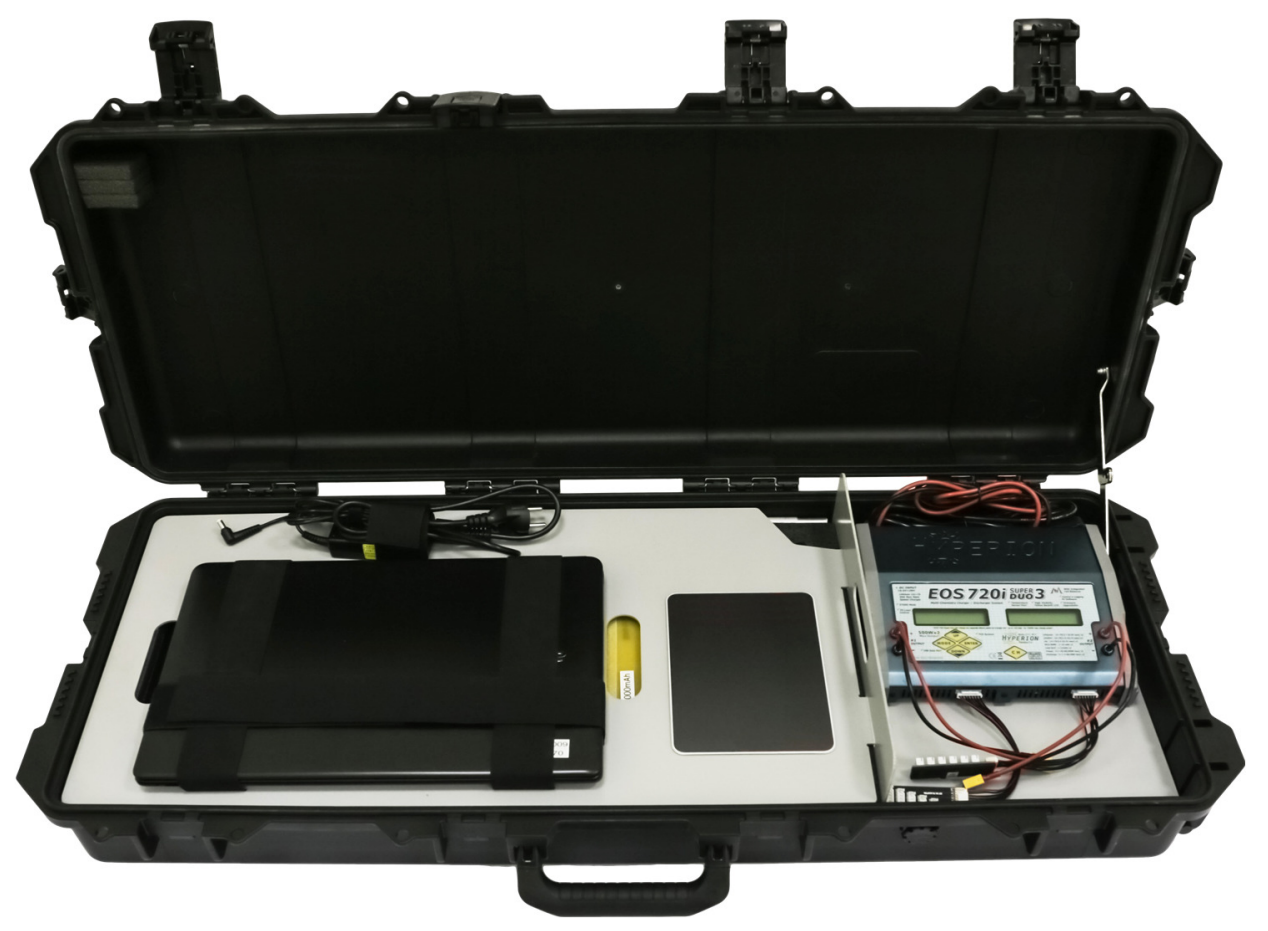

Figure 3. Unmanned aerial vehicle Geoscan 201 ground control system

- Data processing. Cross-linking of images was performed using Agisoft PhotoScan program block layout algorithm. Coordinates of the digital camera photos' central points and orientation angles are taken and then attributed to the thermal images;

- Analysis of results. The total area under study is $3.71 \mathrm{~km}^{2}$, the UAV survey was carried out during 2 days.

A day before the survey, the used geothermal water from the plant was partly discharged onto the surface in order to evaluate UAV based thermal imagery monitoring use in case of unsustainable fluid utilization.

\section{RESULTS}

In 2013, the Grozny State Oil Institute within the consortium 'Geothermal resources' started a pilot project to build a geothermal plant at the Khankala geothermal field of the Chechen Republic (Russia). The deposit is situated $10 \mathrm{~km}$ south-east from its capital Grozny (Figure 4) [23].

Geothermal waters contain in the Middle Miocene Karagan-Chokrak sediments, represented by sandstones with interlayers and lenses of clay. In total 22 productive formations with thickness ranging from a few up to 60 meters are allocated. The content of the geothermal waters in the sediments of the middle Miocene, besides favorable filtration parameters of productive strata, is determined by high heat flow, 
structural-tectonic factor, the movement of groundwater (the water is warmed in the synclinal troughs and then rise to the surface) and lithology of the rocks - the Karagan-Chokrak deposits are in-between the Sarmatian and Maikop clays, which provide conservation of heat [24]. The Khankala geothermal field is a multilayer-type reservoir bordered from the north-east and south-east borders by two reverse faults (Figure 5).

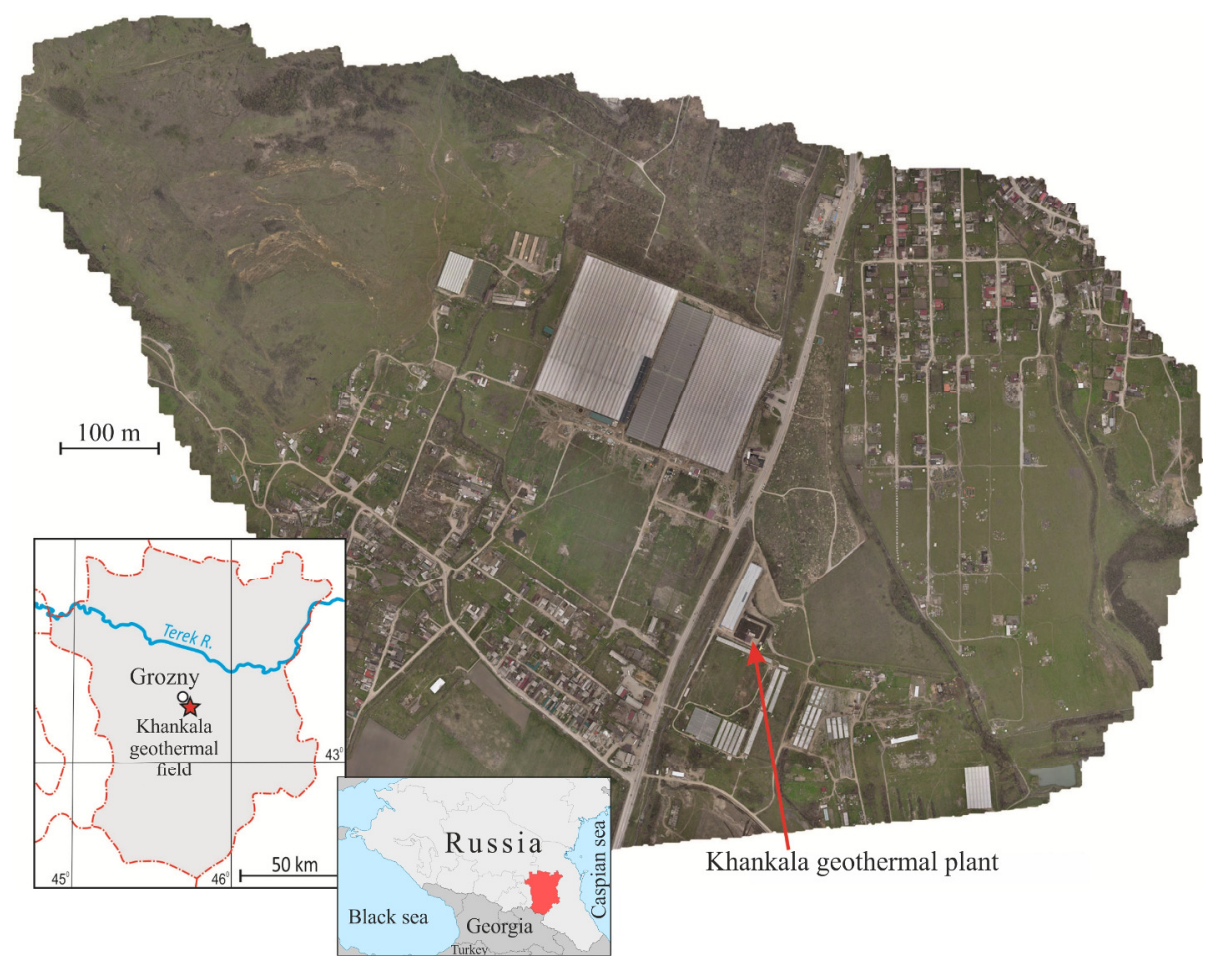

Figure 4. The Khanka geothermal field

Since the beginning of 2016 the geothermal plant of $22.8 \mathrm{GJ} / \mathrm{h}$ capacity is in operation and uses the doublet system - one injection and one production well with full reinjection of water. The consumer of heat is a greenhouse complex.

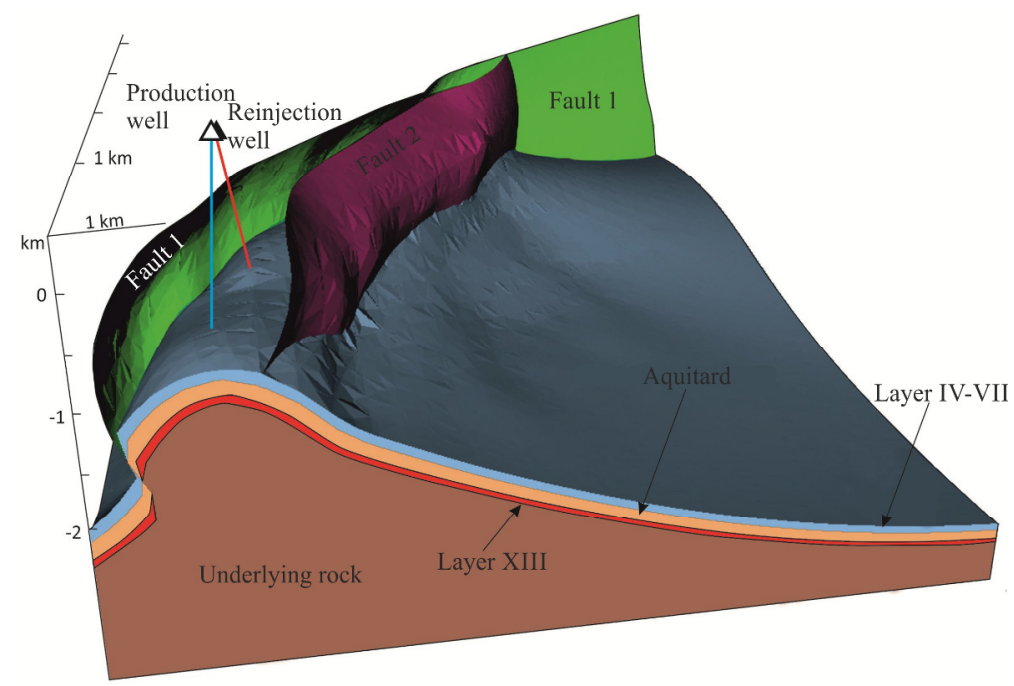

Figure 5. The Khankala geothermal field 3D geological model [25]

The Khankala project is innovative for Russia - it is the only operating geothermal plant with doublet system and $100 \%$ reinjection of used geothermal waters back into 
aquifer (Figure 6). Modern technologies in the field of geothermal waters development were applied during project realization: 3D geological model of the deposit and temperature distribution maps using geostatistical analysis were created, mathematical modeling of temperature changes in the course of reinjection was conducted [26]. Research results allowed to define optimal location, distance between productive and injection well bottoms and geothermal plant operation parameters. In addition, an environmental monitoring using UAV during exploitation of the Khankala geothermal field was performed.

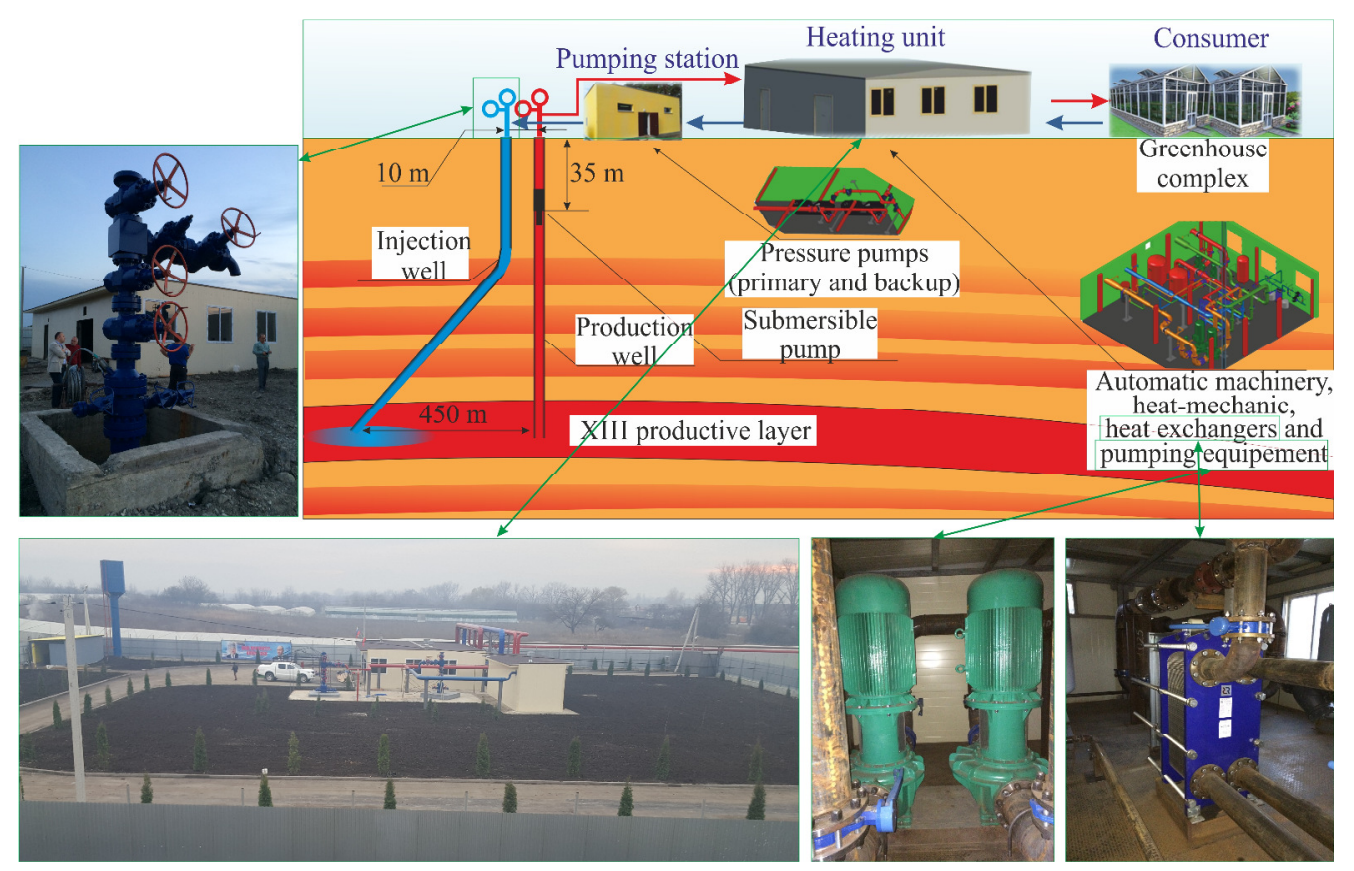

Figure 6. The Khankala geothermal plant [25]

In total, 4,552 visible and thermal images were taken on day 1 and 4,738 visible and thermal images during the day 2. Data processing took two days. Figure 7 shows georeferenced map of the the Khankala geothermal field and adjacent territory as results of photo imaging using the UAV.

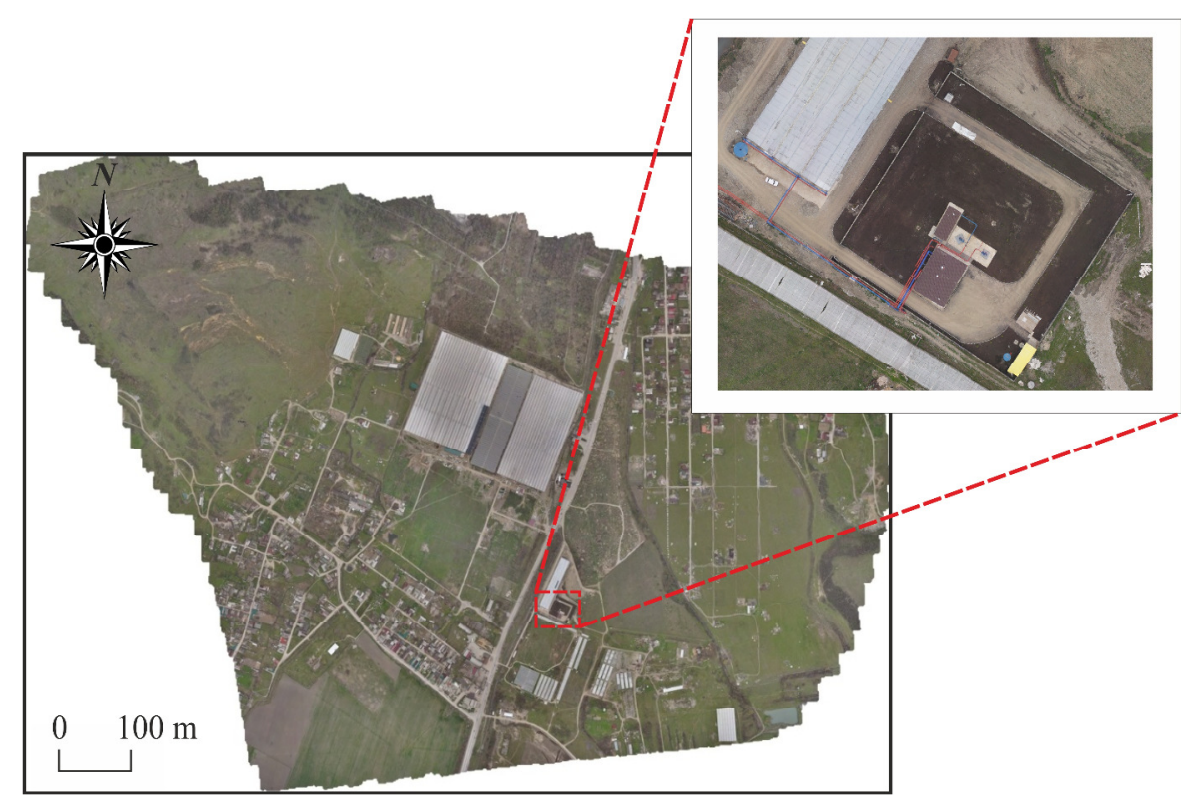

Figure 7. Results of photo imaging 
Two different thermal images of the Khankala geothermal plant under operation were obtained (Figure 8).

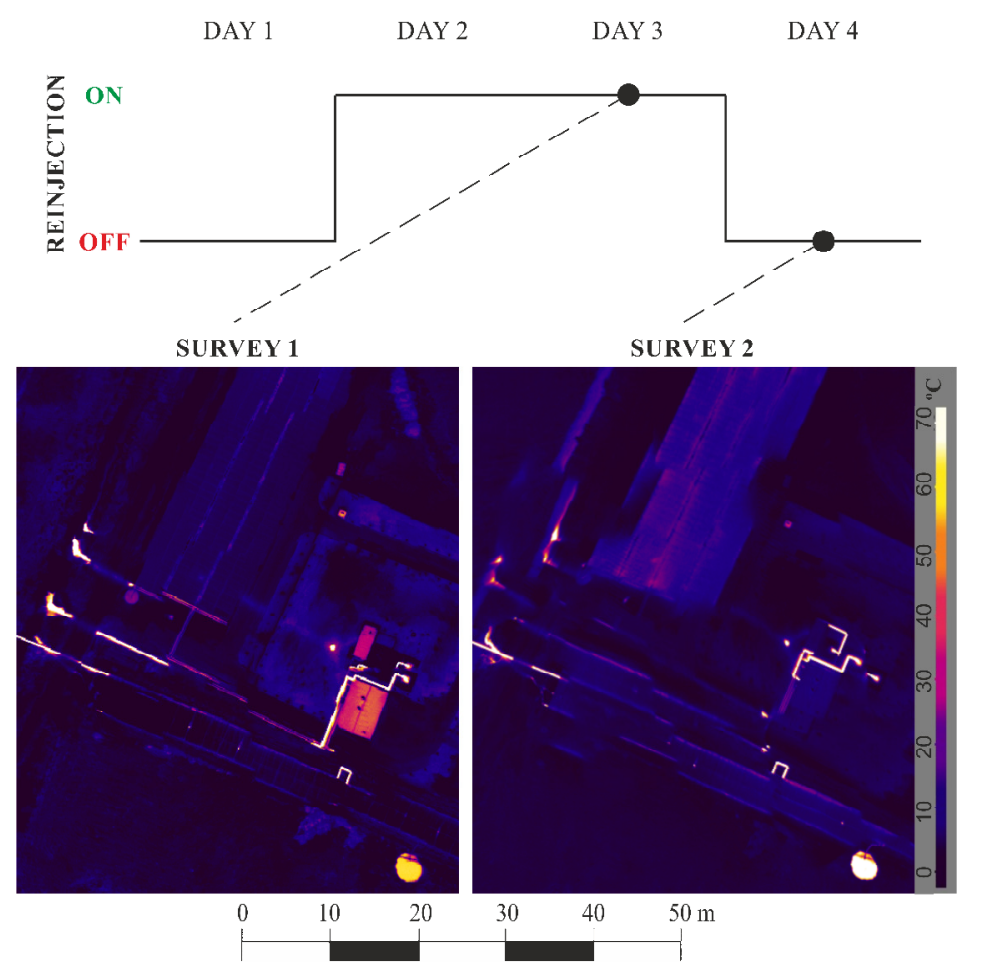

Figure 8. Results of the Khankala geothermal plant thermal imaging under different operation conditions

In the first picture (left), plant and pipelines are "lightened up" because of higher than ambient temperature due to reinjection of used geothermal water regime. In the second picture (right) these elements are cooled down, but artificial small pond (bottom right corner), where thermal fluid was discharged earlier, shows higher temperature.

Besides different images of the geothermal plant under operation, 13 thermal anomalies have been allocated at the territory of the Khankala geothermal field and surrounding area (Figure 9). Analysis of the shape and temperature of the identified anomalies allowed determining their sources: bonfires, wells, heating systems, etc. (Table 3). Subsequently, ground reconnaissance of the study area was carried out to clarify and check the sources of the highlighted anomalies. Coordinates have been determined using GPS navigator.

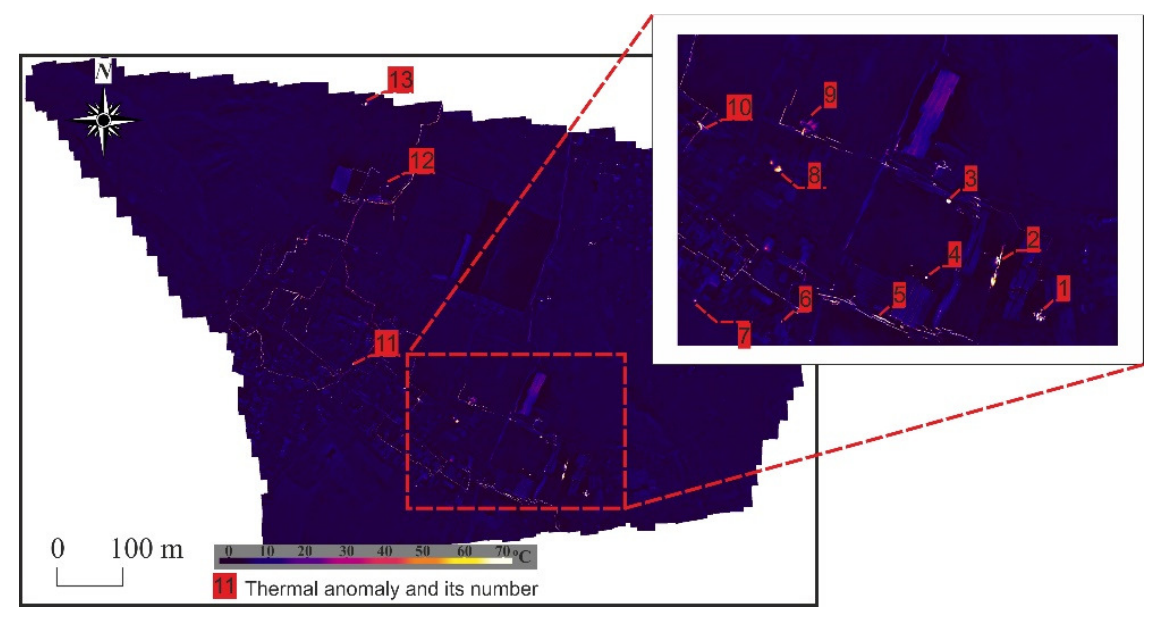

Figure 9. Results of thermal imaging 
Table 3. Examples of the temperature anomalies at the area under study

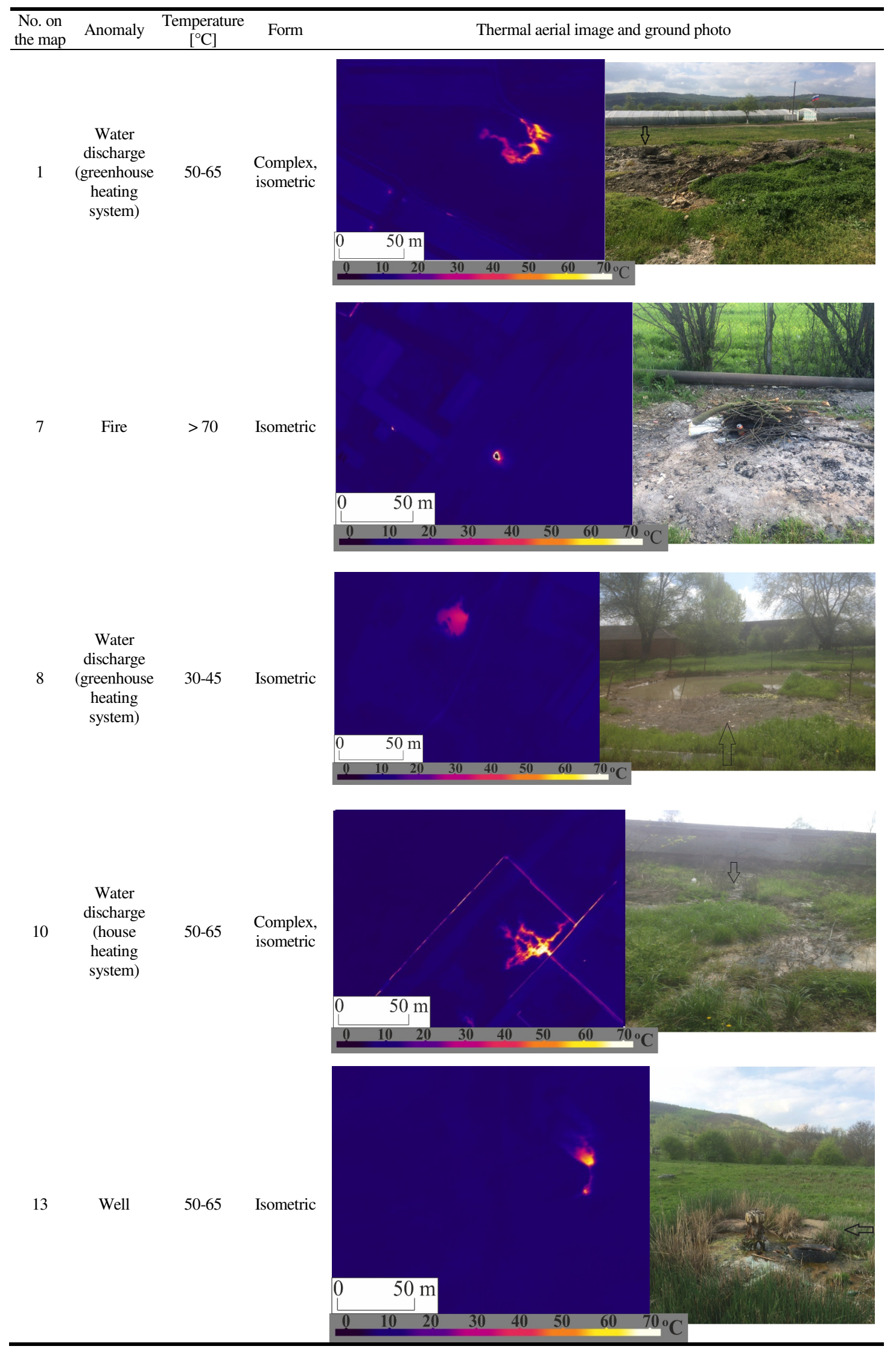

The results of the ground test have confirmed all the previously supposed sources of thermal anomalies' analysis. It should be noted that the shape of anomalies created by hot water discharge at the surface is largely dependent on the terrain. Sufficiently high 
resolution of thermal imaging using the UAV allowed errorless recognition of thermal anomalies within the large area under study.

\section{CONCLUSIONS}

Infrared remote sensing is a unique instrument with high resolution for the environmental monitoring of geothermal areas. Remote sensing by aircraft and space vehicles is a rapidly developing domain of information on the state of environment collection. Carrying out aerial surveys using UAV is considered to be a promising method as thermal imagery using UAV facilitates assessment of the thermal effects of anthropogenic objects on the environment.

UAV infrared imagery of geothermal plant functioning under different regimes (with and without reinjection of the used geothermal water) was done for the first time. The results of the research confirm the possibility and effectiveness of monitoring the geothermal waters exploitation using UAV and thermal imager. Of special interest is an ability of the method not just detection of leaks and spills of thermal water from damaged pipelines or old wells, but, also, the monitoring of geothermal plant functions, such as reinjection of used fluid. The sources of the thermal anomalies recognized during image analysis, were confirmed by the ground reconnaissance with $100 \%$ accuracy. Remote monitoring with automatic recognition methods can be the next step of such a survey.

Aerial technologies have high accuracy and are particularly justified when it is necessary to quickly obtain data at relatively compact (up to $n \times 100 \mathrm{~km}^{2}$ ) area. Unmanned aerial vehicles represent a more cost-effective alternative to a piloted aircraft. Using UAVs is especially prospective for geothermal fields situated at difficult approach territories, which limits the abilities of a ground survey and also for monitoring of complex systems of wells and pipelines, which was the case of the sudy in Khankala geothermal field.

\section{ACKNOWLEDGEMENT}

The research has been executed with support of the Ministry of Education and Science of Russian Federation, contract No. 14.607.21.0081, ID: RFMEFI60714X0081.

\section{REFERENCES}

1. Matek, B., Promoting Geothermal Energy: Air Emissions Comparison and Externality Analysis, Washington, D. C.: Geothermal Energy Association (GEA), 2013, http://geo-energy.org/events/Air\%20Emissions\%20Comparison\%20and\%20Externalit y\%20Analysis_Publication.pdf, [Accessed: 22-June-2017]

2. Kagel, A., Bates, D. and Gawell, K., A guide to Geothermal Energy and the Environment', Geothermal Energy Association: Washington, D. C., 75 p, USA, 2005, https://doi.org/10.2172/897425

3. Cherkasov, S. V., Churikova, T. G., Bekmurzaeva, L. R., Gordeichik, B. N. and Farkhutdinov, A. M., The State and Prospects for the utilization of Geothermal Resources in the Russian Federation, Ecology, Environment and Conservation, Vol. 21, Suppl. Issue, pp 67-77, 2015.

4. Bromley, C. J., van Manen, S. M. and Mannington, W., Heat Flux from steaming Ground: Reducing uncertainties, Thirty-sixth Workshop on Geothermal Reservoir Engineering, Stanford University, Stanford, California, USA, 2011.

5. Heasler, H., Jaworowski, C. and Foley, D., Geothermal Systems and monitoring Hydrothermal Features (Young, R. and Norby, L., eds), Geological monitoring, Boulder, Colorado: Geological Society of America, 2009.

6. Einarsson, G. M. and Kristinsson, S. G., Thermal imaging of Geothermal Features, Proceedings World Geothermal Congress, 9 p, Bali, Indonesia, 2010. 
7. Dawson, G. B. and Dickinson, D. J., Heat Flow studies in Thermal areas of the North Island of New Zealand, Geothermics, Special Issue 2, pp 466-473, 1970, https://doi.org/10.1016/0375-6505(70)90045-3

8. Pálmarsson, G., Friedman, J. D., Williams, Jr. R. S., Jónsson, J. and Sæmundsson, K., Aerial Infrared surveys of Reykjanes and Torfajökull Thermal Areas, Iceland, with a Section on Cost of Exploration Surveys, Geothermics, Special Issue 2, U. N. Symposium on the development and utilization of Geothermal Resources, Vol. 2, Part 1, pp 339-412, Pisa, Italy, 1970, https://doi.org/10.1016/0375-6505(70)90037-4

9. Freidman, J. D., Williams, Jr., R. S., Pórarinsson, S. and Pálmarsson, G., Infrared emission from Kverkfjöll Subglacial Volcanic and Geothermal Area, Iceland, Jökull 22, pp 27-43, 1972.

10. Hodder, D. T., Application of Remote sensing to Geothermal prospecting, Geothermics, Vol. 2, No. 1, pp 368-380, 1970, https://doi.org/10.1016/0375-6505(70)90035-0

11. Mongillo, M. A., Cochrane, G. R. and Browne, P. R. L., Application of Satellite imagery to explore and monitor Geothermal Systems, Proceedings of the World Geothermal Congress, pp 951-956, Pisa, Italy, 1995.

12. Seielstad, C. and Queen, L., Thermal Remote monitoring of the Norris Geyser Basin, Yellowstone National Park, Final Report for the National Park Service Cooperative Ecosystem Studies Unit, Agreement No. H1200040001, 38 p, 2009.

13. Vaughan, R. G., Keszthelyi, L. P., Lowenstern, J. B., Jaworowski, C. and Heasler, H., Use of ASTER and MODIS Thermal Infrared Data to quantify Heat Flow and Hydrothermal change at Yellowstone National Park, Journal of Volcanology and Geothermal Research, Vol. 233-234, pp 72-89, 2012, https://doi.org/10.1016/j.jvolgeores.2012.04.022

14. Allis, R. G., Nash, G. D. and Johnson, S. D., Conversion of Thermal Infrared Surveys to Heat Flow: Comparisons from Dixie Valley, Nevada, and Wairakei, 23 p, New Zealand, GRC Transactions, 1999.

15. Coolbaugh, M. F., Kratt, C., Fallacaro, A., Calvin, W. M. and Taranik, J. V., Detection of Geothermal Anomalies using Advanced Spaceborne Thermal Emission and Reflection Radiometer (ASTER) Thermal Infrared Images at Bradys Hot Springs, Nevada, USA, Remote Sensing of Environment, Vol. 106, No. 3, pp 350-359, 2007, https://doi.org/10.1016/j.rse.2006.09.001

16. Taranik, J. V., Coolbaugh, M. F. and Vaughan, R. G., An overview of Thermal Infrared Remote sensing with Applications to Geothermal and Mineral exploration in the Great Basin, Western United States, Reviews in Economic Geology, Vol. 16, 2009.

17. Watts, A. C., Ambrosia, V. G. and Hinkley, E. A., Unmanned Aircraft Systems in Remote sensing and Scientific research: Classification and considerations of use, Remote Sens., Vol. 4, No. 6, pp 1671-1692, 2012, https://doi.org/10.3390/rs4061671

18. Jordan, B. R., A Bird's-eye view of Geology: The use of Micro Drones/UAVs in Geologic Fieldwork and Education, GSA Today, Vol. 25, pp 42-43, 2015, https://doi.org/10.1130/GSATG232GW.1

19. Nishar, A., Richards, S., Breen, D., Robertson, J. and Breen, B., Thermal Infrared imaging of Geothermal Environments and by an unmanned Aerial Vehicle (UAV): A Case Study of the Wairakei - Tauhara Geothermal Field, Taupo, New Zealand, Renewable Energy, Vol. 86, pp 1256-1264, 2016, https://doi.org/10.1016/j.renene.2015.09.042

20. Harvey, M. C., Rowland, J. V. and Luketina, K. M., Drone with Thermal Infrared Camera provides high Resolution georeferenced Imagery of the Waikite Geothermal Area, New Zealand, Journal of Volcanology and Geothermal Research, Vol. 325, pp 61-69, 2016, https://doi.org/10.1016/j.jvolgeores.2016.06.014

21. Harvey, M., Harvey, C., Rowland, J. and Luketina, K., Drones in Geothermal Exploration: Thermal Infrared Imagery, Aerial Photos and Digital elevation Models, 
Proceedings, $6^{\text {th }}$ African Rift Geothermal Conference Addis Ababa, 12 p, Ethiopia, 2016.

22. Gryadunov, D. A., Mitrofanov, E. V. and Bubenkov, D. I., On applying of the UAV Complexes in Multilevel System of Ecological monitoring, Bulletin of the Moscow State Regional University, "Natural Sciences" Series, No. 4, pp 95-99, 2012.

23. Farkhutdinov, A., Goblet, P., de Fouquet, C. and Cherkasov, S., A Case Study of the modeling of a Hydrothermal Reservoir: Khankala deposit of Geothermal Waters, Geothermics, Vol. 59, Part A, pp 56-66, 2016, https://doi.org/10.1016/j.geothermics.2015.10.005

24. Alhasov, A. B., Renewable Energy Resources: Tutorial, 270 p, Moscow, 2011.

25. Cherkasov, S. V., Report on the Topic: Development of a 3D Digital Model of a Reservoir of Geothermal Waters, Development of an Algorithm for Mathematical modeling of the Temperature distribution within the Reservoir of Geothermal Waters, 65 p., 2013.

26. Farkhutdinov, A., Goblet, P., de Fouquet, C., Ismagilov, R., Farkhutdinov, I. and Cherkasov, S., The use of Computer modelling to forecast the Sustainability in the development of Geothermal waters Resource: Khankala Deposit Example, International Journal of Renewable Energy Research, Vol. 5, No. 4, pp 1062-1068, 2015. 